\title{
Landslides and lineament mapping along the Simpang Pulai to Kg Raja highway, Malaysia.
}

\begin{abstract}
Geological structural features, such as the discontinuities that may be detected on satellite imagery as lineaments, in many cases control landslide occurrences. Lineament may represent the plane of weakness where the strength of the slope material has been reduced, eventually resulting in slope failure. The main objective of this study is to assess the relationship between lineament and landslide occurrences along the Simpang Pulai to $\mathrm{Kg}$ Raja highway, Malaysia. Lineament mapping was undertaken utilizing Landsat imagery and landslide distributions were identified based on field mapping and historical records. Lineament density maps of length, number and intersections were generated and compared with landslide distributions. The lineaments were also visually compared with the landslide occurrences. The results showed that there is an association between the lineaments and landslide distribution. Thus, lineament mapping is essential for the early stages of planning to prevent hazard potential from landslides.
\end{abstract}

Keyword: Lineament; Landslide; Remote sensing. 